LA W RENCE LIVERMORE N A TIONAL LABORATORY

Handling and characterization of glow-discharge polymer samples for the light gas gun

M. C. Akin, R. Chau, Z. Jenei, M. J. Lipp, W. J. Evans

October 10, 2013 
This document was prepared as an account of work sponsored by an agency of the United States government. Neither the United States government nor Lawrence Livermore National Security, LLC, nor any of their employees makes any warranty, expressed or implied, or assumes any legal liability or responsibility for the accuracy, completeness, or usefulness of any information, apparatus, product, or process disclosed, or represents that its use would not infringe privately owned rights. Reference herein to any specific commercial product, process, or service by trade name, trademark, manufacturer, or otherwise does not necessarily constitute or imply its endorsement, recommendation, or favoring by the United States government or Lawrence Livermore National Security, LLC. The views and opinions of authors expressed herein do not necessarily state or reflect those of the United States government or Lawrence Livermore National Security, LLC, and shall not be used for advertising or product endorsement purposes.

This work performed under the auspices of the U.S. Department of Energy by Lawrence Livermore National Laboratory under Contract DE-AC52-07NA27344. 


\title{
Handling and characterization of glow-discharge polymer samples for the light gas gun
}

\author{
M. C. Akin, Z. Jenei, M. J. Lipp, W. J. Evans, and R. Chau \\ Lawrence Livermore National Laboratory, \\ University of California, Livermore, CA 94550
}

(Dated: October 25, 2013)

\begin{abstract}
The equation of state (EOS) of glow discharge polymer (GDP) was measured to high precision using the two-stage light gas gun at LLNL over pressures up to 700 kbar using 90 micron samples. As part of this effort, the GDP samples were characterized extensively, including their variation in initial density, response to curing at ambient conditions, the effect of vacuum exposure, and their initial chemical structure.

This work performed under the auspices of the U.S. Department of Energy by Lawrence Livermore National Laboratory under Contract DE-AC52-07NA27344.

PACS numbers: $61.25 . \mathrm{Em}, 72.80 .-\mathrm{r}, 82.40 . \mathrm{FP}$
\end{abstract}

\section{INTRODUCTION}

The National Ignition Facility uses glow-discharge polymer (GDP) as ablators in its indirect-drive-based inertial confinement fusion program. It is also used on other platforms and programs (e.g., Omega), and is a common material used in laser-driven shock systems. Data about GDP at pressures above 1 Mbar were collected by Barrios et al. ${ }^{1}$ However, their laser-based impedance matching technique relied upon a reflective shock in quartz and thus precluded the collection of Hugoniot data at lower pressures. This region is of particular interest as it includes the release path from the first shock in NIF's four-shock compression scheme, and the dissociation chemistry of GDP. This region is necessary to predict the release of GDP into the DT fuel, and the compression of subsequent shocks. The chemistry of GDP plays a crucial role in this range, because it alters the GDP structure and resulting reshock Hugoniot.

Existing EOS models based on substitute materials, such as polystyrene, diverge from the high-pressure Hugoniot of GDP enough that using them to predict the release of GDP generates too much uncertainty to be useful. Such uncertainty is amplified by the addition of Ge or Si doping, as planned. The high-pressure Hugoniot is also subject to uncertainties caused by choice of quartz standard. To correct these shortcomings in current EOS models, we measured the Hugoniot of GDP at pressures less than 1Mbar using a two-stage light gas gun. To do so required extremely accurate measurement of the density of GDP upon arrival and after handling. Because the samples are much thinner than typically used on a two-stage gun, greater attention was paid to the change in thickness with response to time and vacuum exposure, as well as to initial flatness, structure, and variation in the samples. Due to the use of photon Doppler velocimetry (PDV), measurements of the refractive index of GDP were also made. Many techniques were applied to the handling problem of GDP. Here we describe each method, followed by its results, to improve clarity for the reader.

\section{METHODS AND RESULTS}

\section{A. Visual and Microscopic Characterization}

GDP samples were purpose-grown by General Atomics of San Diego, CA for this experiment. To create disks for this experiment, GDP was grown on a substrate in a dome shape. Due to the growth method, the maximum sample

This document was prepared as an account of work sponsored by an agency of the United States government. Neither the United States government nor Lawrence Livermore National Security, LLC, nor any of their employees makes any warranty, expressed or implied, or assumes any legal liability or responsibility for the accuracy, completeness, or usefulness of any information, apparatus, product, or process disclosed, or represents that its use would not infringe privately owned rights. Reference herein to any specific commercial product, process, or service by trade name, trademark, manufacturer, or otherwise does not necessarily constitute or imply its endorsement, recommendation, or favoring by the United States government or Lawrence Livermore National Security, LLC. The views and opinions of authors expressed herein do not necessarily state or reflect those of the United States government or Lawrence Livermore National Security, LLC, and shall not be used for advertising or product endorsement purposes. This work performed under the auspices of the U.S. Department of Energy by Lawrence Livermore National Laboratory under Contract DE-AC52-07NA27344. 


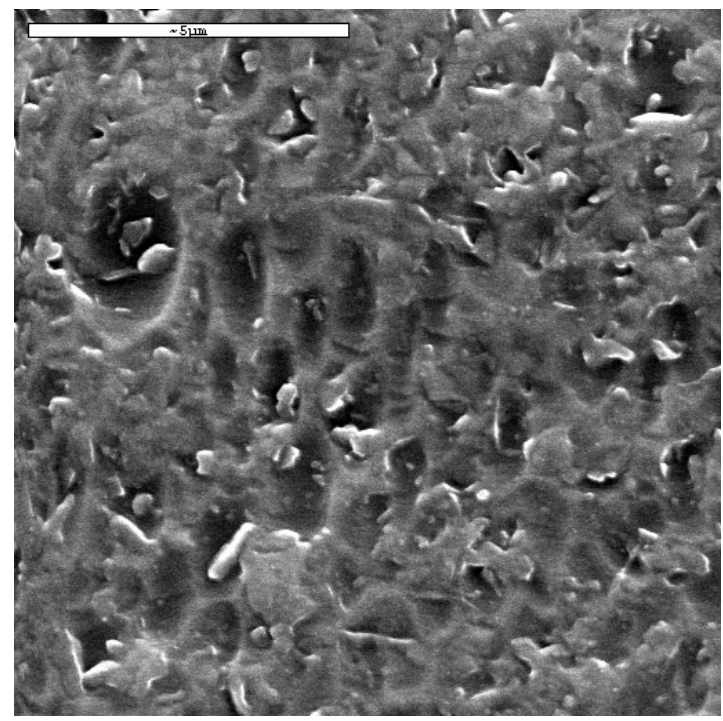

(a) machined side

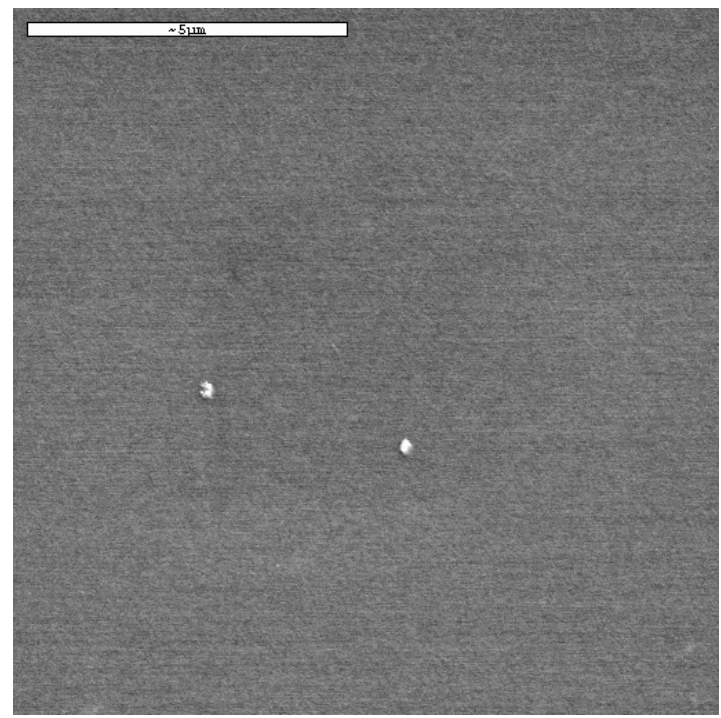

(b) as-grown side

FIG. 1: Scanning electron micrograph of the a) machined, or "rough" side and b) the as-grown, "smooth," or "shiny" side of the GDP sample. Reference bar is 5 microns.

thickness that could be grown is roughly 180 microns. The dome was then machined into steps and sample disks of $5.75 \mathrm{~mm}$ diameter were laser cut from the substrate by General Atomics. The strain inherent in the growth and cutting process leads to cupping and rippling deformation of the disks (e.g., they are shaped like potato chips, rice bowls, etc.), which complicated volumetric measurements. Each sample is dark brown, and has one shiny side and one rough side, which correspond to the substrate-grown and machined sides, respectively. The machining process causes a notable amount of chipping and surface roughening, as seen in Figure 1a, which was imaged using scanning electron microscopy (SEM). This chipping spans the entire machined surface, but is not seen on the as-grown side. Prior SEM images of other GDP samples that were not machined are very similar to the as-grown image, so the chipping appears to be a function of the micro cutting process. Chips are 1-3 $\mu \mathrm{m}$ in size and generally oval shaped. The depth of the chip-out regions could not be determined. Some evidence of work heating/melting is apparent in images where small $\sim 1 \mu \mathrm{m}$ chunks appear to be smeared out or press melted back to the surface.

\section{B. Infrared measurements}

The as-grown samples differed markedly in appearance from other samples of GDP used as a reference, which were 50 and $70 \mu \mathrm{m}$ thick and a light honey color. Fourier Transform Infrared spectroscopy (FTIR) measurements were taken under $\mathrm{N}_{2}$ atmosphere to confirm composition and structure of the as-grown samples using a Perkin-Elmer Spectrum 2000 FTIR and a beam condenser. FTIR also allowed us to confirm the transmission of the Photon Doppler Velocimetry (PDV) laser for the shots. FTIR spectra were collected of the 92 and 172 micron thick samples upon their arrival at LLNL (that is, freshly made GDP samples prior to any other handling or storage). Interference fringes are clearest in the 92 micron sample, but are also present in the 172 micron sample (Fig. 2a). These fringes were used to cross-check LaseRule measurements of the thickness discussed below. These thickness measurements agree within the uncertainty of the refractive index.

The strongest absorption covers the range $2860-2940 \mathrm{~cm}^{-1}$, and suggests that the $\mathrm{C}-\mathrm{H}$ stretches are primarily $\mathrm{sp}^{3}$ (Figures 2a and $2 \mathrm{~b}$ ). The overtones located at 5680-5870 $\mathrm{cm}^{-1}$ suggest three $\mathrm{C}-\mathrm{H}$ stretching modes are present in this region. A simple analysis, assuming the overtone is exactly twice the fundamental frequency, estimates the fundamental bands to be 2841, 2905, and $2932 \mathrm{~cm}^{-1}$, consistent with $\mathrm{sp}^{3}$. An alternate analysis that extrapolates the edges of the broader band suggests that the highest fundamental frequency is as high as $3030 \mathrm{~cm}^{-1}$, which would suggest some $\mathrm{sp}^{2}$ nature. As the signal in the fundamental region is saturated, these two analyses cannot be distinguished.

The second strongest absorption occurs at $1704 \mathrm{~cm}^{-1}$, obviously a carbonyl stretch, but somewhat on the low side of the typical stretching region-as would be expected if paired with a conjugated system. The presence of a second strong band at $1610 \mathrm{~cm}^{-1}$ confirms a double bond in conjugation with the ketone. There is no evidence of 
the expected alkene stretch between $3000-3100 \mathrm{~cm}^{-1}$, so we conclude that any C-H stretching bands associated with alkenes in this range are overwhelmed by the main band at $2860-2940 \mathrm{~cm}^{-1}$. It is possible that the band at 1600 $\mathrm{cm}^{-1}$ is superimposed on the carbonyl band, or otherwise pumped, and thus appears more prevalent than it is. The strong typical bands for alkynes, alkenes, and aromatics at wavenumbers above 3000 are absent, which suggests that the structure has a greater saturated component than would be suggested by the $1600 \mathrm{~cm}^{-1}$ band, and confirms an aliphatic structure. Additional strong bands are observed at 1377 and $1460 \mathrm{~cm}^{-1}$, consistent with $\mathrm{C}-\mathrm{H}$ stretches and bends.

The effect of aging on the IR spectrum was also measured (Fig. 2b). Our reference samples of GDP had been aged, as are NIF capsules, so this was the best way to compare composition and structure of our as-grown samples. The 50 and 70 micron reference samples were received after aging at ambient conditions (there were no fresh 50 and 70 micron samples to test); the 92 and 172 micron as-grown samples were aged in a jar of Drierite. "Fresh" 92 and 172 micron samples were measured immediately upon arrival from General Atomics; "aged" samples were measured about three months later. A strong broad band centered at $3400 \mathrm{~cm}^{-1}$ had the most notable change in both sample thicknesses, strengthening and broadening with age, which we assign to a $\mathrm{OH}$ stretch. Some weak absorptions are noted at $3180,3400,3480$, and $3620 \mathrm{~cm}^{-1}$ in the fresh samples. These bands disappear in the aged samples or are merged into the growing -O-H stretch band. We tentatively assign the band at 3620 to a free $\mathrm{OH}$ group whose steric hindrance is removed as the plastic ages and relaxes. Additional bands at 1060, 1150, and 1700 indicate that the oxygen is present in a variety of forms, including ketones, alcohols, and possibly carboxylic groups. A sharp band located at $2731 \mathrm{~cm}^{-1}$ was unaffected by aging; it could be either a possible aldehyde $\mathrm{C}-\mathrm{H}$ stretch, or an overtone of the strong $1377 \mathrm{~cm}^{-1}$ band. The strong absorptions observed at 1380, 1610, and $1710 \mathrm{~cm}^{-1}$ strengthened/broadened with aging, but were not as pronounced as the change due to the $\mathrm{OH}$ stretch. This change reflects the absorption of water and other species by GDP during sample handling and metrology. The uptake of water into the plastic with age is quite clear in the spectrum, and also has the effect of strengthening the carbonyl bands while washing out adjacent bands. This complicates the assignment of frequencies, so many weak bands were left unassigned in Table IV. These results indicate that our samples are the same as our reference samples, and confirms that GDP takes up oxygen (either $\mathrm{O}_{2}$ or $\mathrm{H}_{2} \mathrm{O}$ ) as it ages.

\section{Density Measurements}

Each sample was measured using a Mettler Toledo XP2U microbalance with $0.1 \mu \mathrm{g}$ precision. Measurements were repeated a minimum of three times; the average value was used to determine the density, and the standard deviation the error. The largest observed total difference in initial weight measurements on a single sample was $0.7 \mu \mathrm{g}$, and the standard deviation was typically $0.1-0.3 \mu \mathrm{g}$. Approximately six months later all samples were re-weighed and found to have increased approximately $3 \%$ (See Table III); in fact, the sample weights were observed to increase steadily (at roughly 0.1-0.2 $\mu \mathrm{g}$ per $15 \mathrm{~s}$ ) while being weighed. The weight increase was not observed for a $100 \mathrm{mg}$ non-porous calibration weight. This second weighing happened on a foggy day where the humidity was much higher, and we believe is due to water and oxygen uptake by the sample. If the uptake is due to the absorption of $\mathrm{O}$, this result suggests an uptake rate of $6 \times 10^{-10} \mathrm{~mol} \mathrm{~s}^{-1}$.

Because the sample sizes are small, the density low, and the GDP susceptible to liquid solvent (including water) uptake, volume displacement density measurements were not feasible. To determine the surface area, samples were imaged using a 60x microscope with a calibrated $\mathrm{mm}$ ruler in the field. Pixel $/ \mathrm{mm}$ ratios were determined for each image, and ranged from 221.56 to 222.52 pixels $/ \mathrm{mm}$. ImageJ software was used to isolate the appropriate ellipse area and count pixels. Areas of the disks were measured before, during, and after compression using the microscope to determine the degree that the area changed. These area changes were minimal so initial measurements were used. However, because of the cupping of the individual sample, identifying the edge can present issues. To estimate the uncertainty resulting from possible misidentification of edges, pixel counts were made of the "edge width" at the 3,6 , 9, and 12 o'clock positions on each sample. The edge width, or uncertainty in the edge location, was found to range from 3 to 10 pixels, or 13-45 microns, across all samples, with a mean of 24 microns. Variation in these measurements and in determining the appropriate edges are tabulated in Table I. To estimate the uncertainty in the area determined by ImageJ, we assumed that the samples were perfectly circular, and that the uncertainty in the radius was one half of the mean edge width for that sample.

Thickness was measured using two different methods. The first attempt to measure thickness used an IR spectrometer (see comments in IR measurement section). IR absorption spectroscopy showed that the purpose grown samples had significantly lower water levels than aged samples left exposed to atmosphere. Transmission in the 7800-5000 $\mathrm{cm}^{-1}$ range was excellent, and interference fringes were observed in samples of both thicknesses. Using a refractive index of $\eta=1.5$, determined through oil-matching, ${ }^{2}$ the thick sample was found to be $180.5 \mu \mathrm{m}$ thick, while the thin sample was found to be $95.5 \mu \mathrm{m}$ thick through application of Equation 1. 


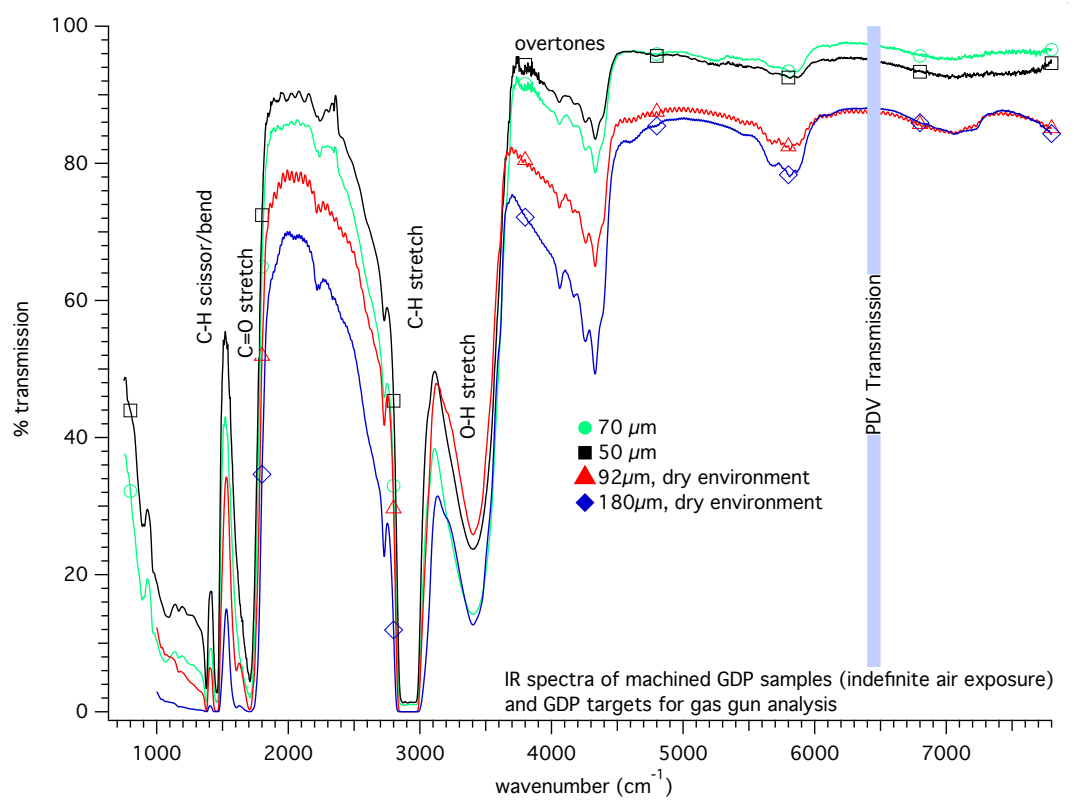

(a) FTIR spectrum of GDP

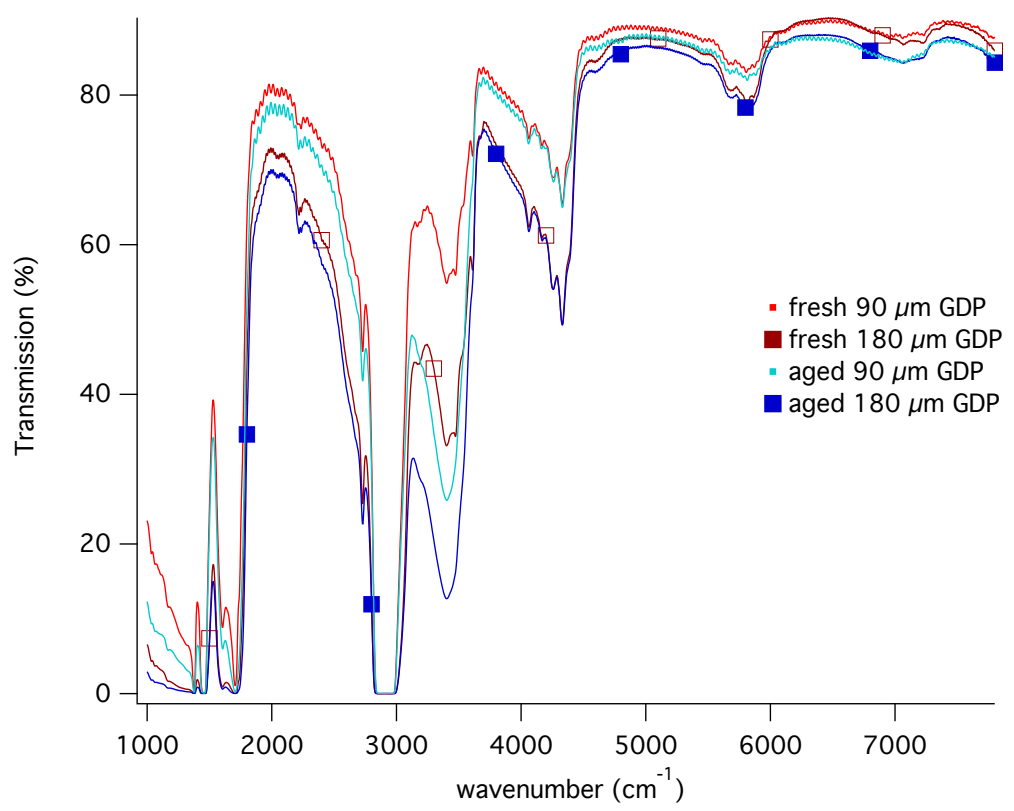

(b) FTIR spectrum of aged GDP

FIG. 2: Effect of a) thickness and b) age upon FTIR spectra of GDP, including the samples that were shot on the gas gun. Thicknesses measured in subfigure a) were roughly 50, 70, 90, and 170 microns. To determine the effect of aging, "fresh" samples were measured as soon as possible after receiving them from General Atomics. The same samples were aged approximately three months under dry storage and measured again. The most noticeable changes are in the $\mathrm{O}-\mathrm{H}$ and $\mathrm{C}=\mathrm{O}$ stretching regions, indicating the uptake of $\mathrm{O}_{2}$ and $\mathrm{H}_{2} \mathrm{O}$. 


$$
h=\frac{n}{2\left(\nu_{1}-\nu_{2}\right) \sqrt{\eta^{2}-\sin ^{2} \theta}}
$$

where $h$ is the thickness; $n$ is the number of fringes; $\nu_{1}, \nu_{2}$ are the frequencies in $\mathrm{cm}^{-1} ; \eta$ is the refractive index; and $\theta$ is the angle of incidence (zero in our system).

It was not feasible to measure the sample thickness across the entire sample surface using this technique, so a LaseRule VLM 200 with precision of $1 \mu \mathrm{m}$ was used to metrologize the sample thickness at thirteen points on each side (to account for rice-bowl effects). The smaller average value was used as the sample thickness, as cupping could artificially increase the apparent thickness. These results are shown in Table V. ${ }^{5}$

Immediately before and after being coated with Ag to improve reflectivity for the PDV probes, each sample thickness was measured at 13-16 points on each side. At this point most samples were observed to have swelled during storage, despite best efforts to minimize exposure to water and other solvents. See Table V. The sample was then coated on the machined side for 5 minutes with silver and re-measured at thirteen to sixteen points with the coating side up. While this did not appear to damage the coating or create any observable pinholes in the coating, it was not repeated with the coating side down (shiny side up) in order to prevent possible damage.

This measurement was done to determine the actual thickness of the Ag coating, which is less than one micron in all cases, based on witness plates. However, the apparent thickness of the coated GDP sample 5, the first attempt, decreased following the coating procedure. This result prompted a small study of the effect of vacuum exposure without Ag coating on the apparent thickness of the sample using samples 2, 3, and 6. These samples were exposed to pressures $<20$ mTorr for 10-15 minutes, which are typical exposures for our sputter coater. Subtle increases in mean thickness were found on the three samples, and cupping effects were found to worsen upon vacuum exposure (Table V). However, these changes were insignificant at the $3 \sigma$ level. Samples were also measured before and after Ag coating; all four samples again show a trend of decreased thickness after coating, but one that is not statistically significant at the $3 \sigma$ level. The sample is exposed to vacuum again in the gun's target chamber for extended periods. Therefore, accurate determination of GDP's density immediately prior to shooting the target requires further study. In our calculations we use the most recent weight and thickness measurements to determine density prior to shooting, according to equation 2 :

$$
\rho=\frac{m}{h a}
$$

where $m$ is mass and $a$ is area. If the observed thickness change was due to the desorption of water vapor, then the initial density of about $1.06 \mathrm{~g} / \mathrm{cc}$ would be most applicable; however, if the thickness change was due to void space collapse without any corresponding desorption, then the upper limit of density should be used instead. Because the sample is held under compression in the target while exposed to vacuum in the target chamber, the expansion under vacuum hinted at in Table V is expected to be minimal. Due to possible distortions in the plastic, or possible reactions between the GDP and the LiF window, this assumption may require a density correction. Initial densities are shown in Table II. Increases in density with aging are shown in Table III. The samples typically gained $3-4 \%$ in weight as they aged. Due to the variation in initial density and the time- and exposure-dependent weight gain of the samples used in each shot, Hugoniot plots should reflect compression rather than density changes.

\section{Porosity Measurements}

Due to difficulties measuring volume of a single sample and the variation in density from sample to sample, an alternate method of volume determination was sought. To this end, a 1-cc gas pycnometer, which relies upon $\mathrm{N}_{2}$ displacement to determine volume, was used. The small size of the samples required that all seven samples be in the chamber simultaneously to obtain a volume; their collective volume was $0.0156 \mathrm{cc}$, with a collective mass of $0.0199 \mathrm{~g}$. The pycnometer-measured bulk density was $1.2769 \pm 0.0076 \mathrm{~g} / \mathrm{cc}$. This result is approximately $18 \%$ higher than the density determined using the method described above, indicating a significant degree of open pores, void space, and other microstructure within the sample available to nitrogen gas. The gas pycnometry measurement was repeated on well-characterized hollow spherical samples with a wall thickness of 42 microns. Results were consistent with rapid nitrogen permeation and diffusion into the sample.

\section{E. Surface Roughness}

A Veeco Waiko NT9800 was used to characterize the surface roughness and local variation of the sample. However, the new samples, when uncompressed, had too much variation in total height to be properly imaged over their entire 


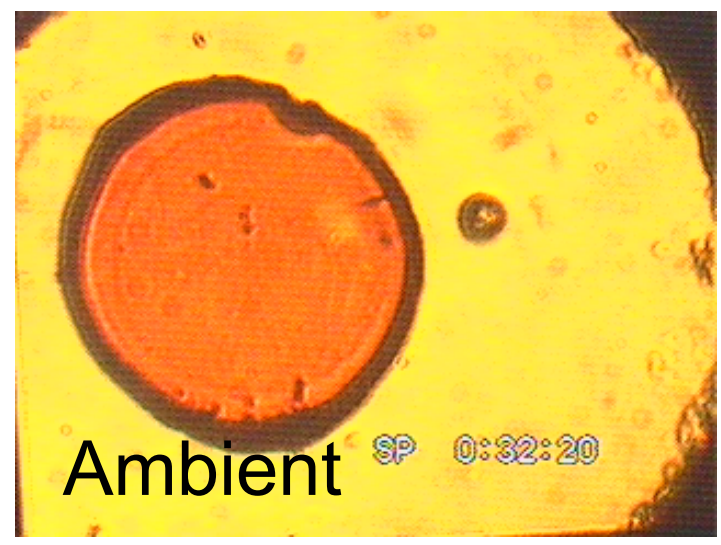

(a) GDP at ambient pressure

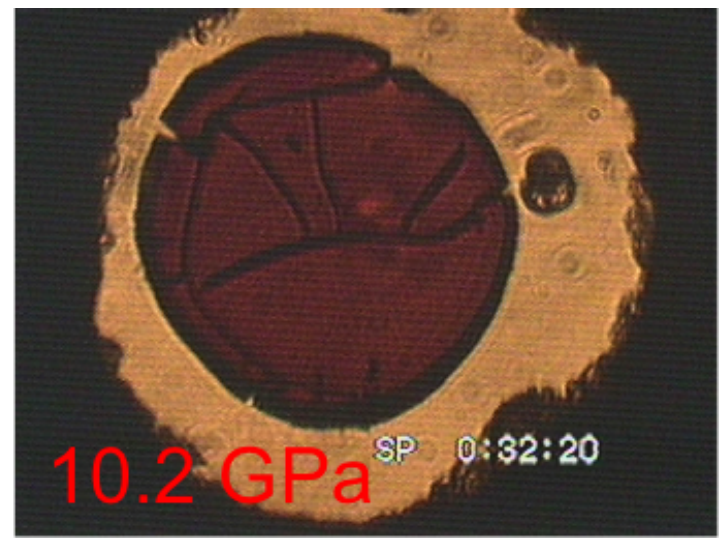

(b) GDP at $10.2 \mathrm{GPa}$

FIG. 3: Images of GDP in the diamond anvil cell at ambient pressure and 10.2 GPa. Images collected by Z. Jenei.

surface. While characterizing the uncompressed samples, a regular super-pattern of peaks and valleys was observed. We suggest that this may be due to the growth substrate or light interference in the Waiko. Under these conditions, the strain in the material led to total surface roughness of up to $6.2 \mu \mathrm{m}$. Targets were re-imaged with the Waiko after 3-4 months and some additional handling. Over this period, the targets appeared to relax, becoming flatter overall, and enabling better measurements of surface roughness by the Waiko. At this later date, the local surface roughness on each sample ranged from 80 to $130 \mathrm{~nm}$.

\section{F. Window correction factor and refractive index measurements}

Velocity measurements through a window using PDV require a correction factor based upon the refractive index at zero density. ${ }^{3}$ The use of PDV, and the need on some shots to correct for double-windowing, required the measurement of the refractive index correction factor of GDP. We attempted to measure the refractive index in a diamond anvil cell to determine its sensitivity with pressure. White light interferometry was used to determine the refractive index up to $10 \mathrm{GPa}$. The variation in the refractive index was significant, due in part to the native absorption in the visible spectrum by the GDP (Figure 3a,3b), which became more pronounced with pressure. As a result, no clear trend in refractive index with respect to pressure or wavelength could be found using this method (Figure 4).

An alternate technique was employed to find the correction factor $\chi$. A $70 \mu \mathrm{m}$ GDP window was used in place of one of the outer LiF windows and the velocities of the free GDP surface and the Al/GDP interfaces were simultaneously measured. The free surface is assumed to move at double the particle velocity. The final observed velocity of the $\mathrm{Al}$ baseplate was then multiplied by 0.5 to determine the true $U_{p}$.

$$
\frac{2 U_{p, \text { apparent }}}{U_{f s}}=\frac{U_{p, \text { apparent }}}{U_{p, \text { true }}}=\chi .
$$

We find that a window correction factor of 1.01 should be applied. A second approach to find the window correction factor using the method of Fratanduono et $\mathrm{al}^{4}$ results in a correction of 1.02-1.03. For our analysis, we use a value of 1.02. The excellent agreement of $U_{p}$ and $U_{s}$ on a subsequent shot, where both were measured independently, indicates that this value is most reasonable.

To date, materials studied have shown a linear dependence of refractive index with density. We assume the same is true for GDP. Consequently, our best determination of the refractive index's dependence on density at $1550 \mathrm{~nm}$ is

$$
n_{1550}=1.02 \pm .01+0.495 \pm .01 \rho
$$

\section{CONCLUSIONS}

This study was initially undertaken solely to confirm that the received samples were the same as the GDP used in NIF, and to determine the refractive index correction factor used in PDV analysis. The IR spectra of GDP samples 


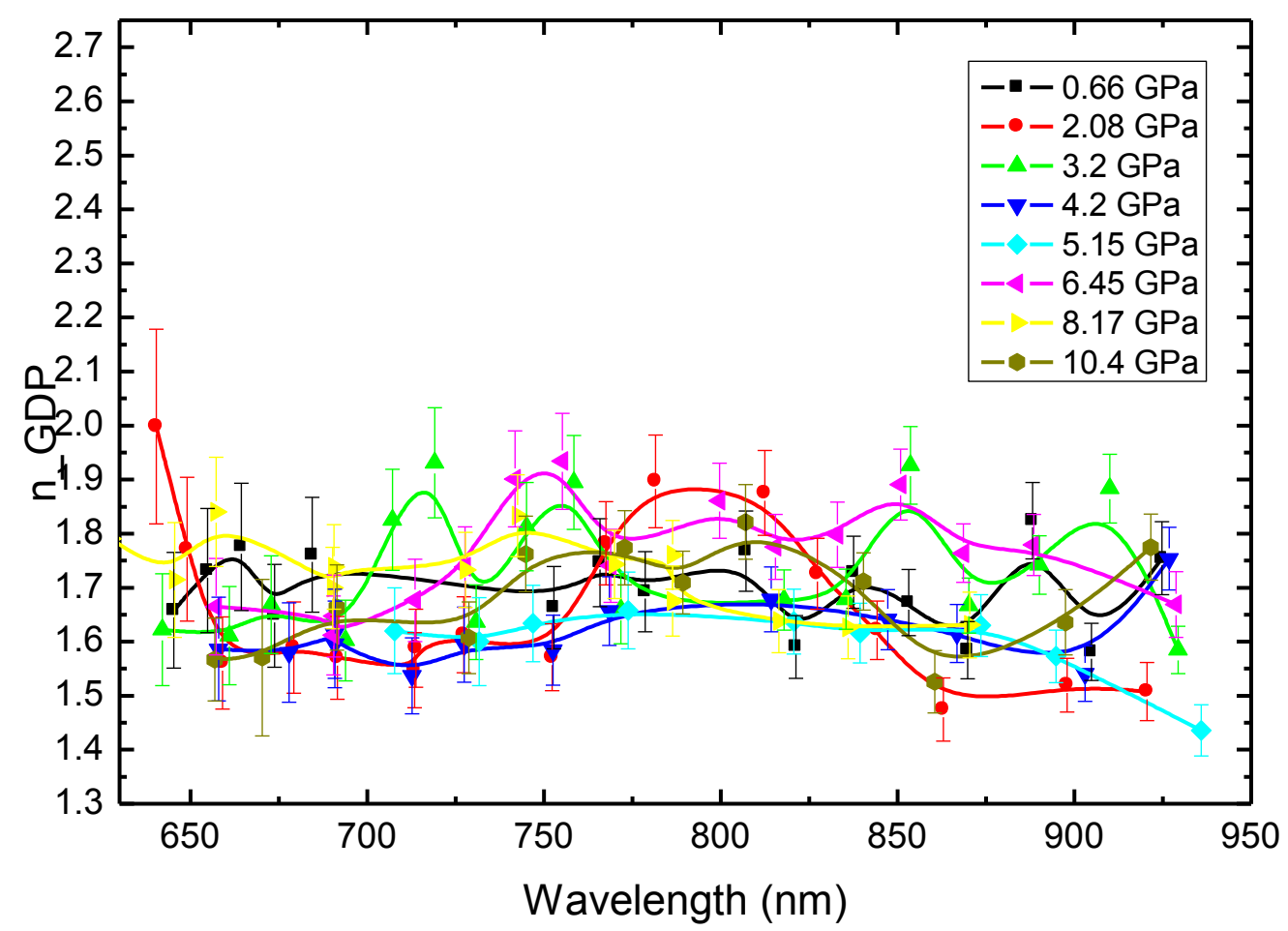

FIG. 4: Refractive index of GDP as measured in the DAC at pressures up to $10 \mathrm{GPa}$. No clear trend in refractive index is apparent with respect to either pressure or wavelength. Data collected by Z. Jenei.

from NIF were identical, confirming that the plastics are the same or very similar. The correction factor was found to be 1.02 .

However, due to the unexpected results seen upon imaging, this study expanded. GDP was found to be sensitive to handling and processing, showing significant chipping and possible work heating due to machining as well as increased cupping upon vacuum exposure. IR spectroscopy and weight measurements of GDP showed it to be sensitive to atmospheric conditions, particularly the uptake of oxygen in the form of - $\mathrm{OH}$, changing its initial density, chemical structure, and macroscopic structure. These conditions are difficult to avoid in the handling and preparation of GDP. We see no evidence of aromatic structure in the GDP, suggesting that computational models of the chemistry of GDP, many of which are built assuming some polystyrene-like structure, may need to be refined. Porosity measurements suggest that some consideration should be given to porous structures as well, though diffusion times were consistent with those provided by GA.

Analysis of GDP will be complicated by these changes and by initial conditions in the GDP. Initial variation in the density of GDP was roughly $3 \%$, and is worsened by handling and processing. Upon aging it was found to increase mass, presumably due to its increased oxygen content, although not in a well-controlled manner. As a result, any calculations of pressure or density in shocked GDP, e.g., Hugoniot measurements, will require the measurement of the individual sample density. Bulk or averaged measurements of initial density should be avoided if initial precision better than $3 \%$, or indeed a Hugoniot measurement better than an optimistic 5\%, is desired.

\section{ACKNOWLEDGEMENTS}

The authors wish to thank the many people without whom this study would not have been executed. Peter Hsu, LLNL, for pycnometry measurements. Walt Unites, LLNL, for imaging samples and the use of his microscope. Jim Hughes, LLNL, Waiko operator. Chris Dawedeit and Alex Hamza, LLNL for use of the microbalance. Steve Letts, LLNL, for the use of his FTIR, his assistance, and many insightful discussions. Ed Lindsey and Monika Biener, LLNL, for SEM images. Al Ellis and Bo Chow, LLNL, for Keyence imaging of a representative sample to determine damage 
done by handling. Zsolt Jenei, Magnus Lipp, and Will Evans, LLNL, for diamond anvil cell studies to determine refractive index. Sam Weaver, Cory McLean, Steve Caldwell, Paul Benevento, Bob Nafzinger, and Jim van Leuwen, for gun operation and target/bullet construction.

1 M. A. Barrios, D. G. Hicks, T. R. Boehly, D. E. Fratanduono, J. H. Eggert, P. M. Celliers, G. W. Collins, and D. D. Meyerhofer, Physics of Plasmas 17, 056307 (2010).

2 Steve Letts, personal communication.

3 B. J. Jensen, D. B. Holtkamp, P. A. Rigg and D. H. Dolan, J. Appl. Phys. 101 (1), 013523 (2007). B. J. Jensen, D. B. Holtkamp, P. A. Rigg and D. H. Dolan, J. Appl. Phys. 106 (4), 049901 (2009).

${ }^{4}$ D. E. Fratanduono, J. H. Eggert, T. R. Boehly, M. A. Barrios, D. D. Meyerhofer, B. J. Jensen and G. W. Collins, J. Appl. Phys. 110 (8) (2011).

5 Applying the mean value to Equation 1, the refractive index at $1550 \mathrm{~nm}$ is approximately 1.55.

\section{TABLES}


TABLE I: Uncertainty estimates in measured area of GDP samples upon arrival. Samples were imaged using a 60x microscope and a calibrated ruler. Possible edges were visually identified based on contrast; "edge width" is the range in pixels of those edges. Edge width was measured in pixels and in microns at clock positions 12, 3, 6, and 9.

\begin{tabular}{|c|c|c|c|c|c|c|c|}
\hline \multicolumn{8}{|c|}{ edge width, pixels } \\
\hline Clock & \multicolumn{7}{|c|}{ sample number } \\
\hline position & 1 & 2 & 3 & 4 & 5 & 6 & 7 \\
\hline 12 & 6 & 5 & 3 & 2 & 6 & 4 & 3 \\
\hline 3 & 7 & 11 & 3 & 3 & 4 & 3 & 4 \\
\hline 6 & 7 & 7 & 2 & 2 & 3 & 2 & 4 \\
\hline 9 & 6 & 8 & 2 & 3 & 4 & 3 & 5 \\
\hline pixels $/ \mathrm{mm}$ : & 245.3 & 247.6 & 251.7 & 244.2 & 265.1 & 250.8 & 151.2 \\
\hline \multicolumn{8}{|c|}{ edge width, $\mu \mathrm{m}$} \\
\hline Clock & \multicolumn{7}{|c|}{ sample number } \\
\hline position & 1 & 2 & 3 & 4 & 5 & 6 & 7 \\
\hline 12 & 24.5 & 20.2 & 11.9 & 8.2 & 22.6 & 15.9 & 19.8 \\
\hline 3 & 28.5 & 44.4 & 11.9 & 12.3 & 15.1 & 12.0 & 26.5 \\
\hline 6 & 28.5 & 28.3 & 7.9 & 8.2 & 11.3 & 8.0 & 26.5 \\
\hline 9 & 24.5 & 32.3 & 7.9 & 12.3 & 15.1 & 12.0 & 33.1 \\
\hline mean: & 26.5 & 31.3 & 9.9 & 10.2 & 16.0 & 12.0 & 26.5 \\
\hline
\end{tabular}

TABLE II: GDP sample density characterization upon receipt. Density is calculated from measured weight, thickness $h$, and area. Note that samples varied by roughly $3 \%$ upon arrival.

\begin{tabular}{|l|r|r|r|r|}
\hline Sample & mean wt $(\mathrm{mg})$ & mean $h(\mathrm{~mm})$ & area $\left(\mathrm{mm}^{2}\right)$ & $\rho\left(\mathrm{mg} / \mathrm{mm}^{3}\right)$ \\
& $\sigma$ wt $(\mathrm{mg})$ & $\sigma h(\mathrm{~mm})$ & $\Delta$ area & $3 \sigma, \rho$ \\
\hline 1 & 2.40363 & 0.0912 & 24.39 & 1.080 \\
& 0.00012 & 0.0004 & 0.16 & 0.017 \\
\hline 2 & 2.4442 & 0.0925 & 24.90 & 1.0617 \\
& 0.0010 & 0.0011 & 0.20 & 0.038 \\
\hline 3 & 4.65373 & 0.1732 & 25.57 & 1.051 \\
& 0.00012 & 0.0004 & 0.06 & 0.008 \\
\hline 4 & 2.4036 & 0.0912 & 24.88 & 1.059 \\
& 0.0003 & 0.0004 & 0.06 & 0.015 \\
\hline 5 & 2.4325 & 0.0924 & 24.84 & 1.060 \\
& 0.0003 & 0.0005 & 0.10 & 0.017 \\
\hline 6 & 2.42457 & 0.09200 & 25.13 & 1.049 \\
& 0.00017 & 0.00000 & 0.08 & 0.003 \\
\hline 7 & 2.4277 & 0.0921 & 24.86 & 1.061 \\
& 0.0002 & 0.0003 & 0.17 & 0.012 \\
\hline
\end{tabular}


TABLE III: The role of aging (and associated water/oxygen uptake) on the measured weight of GDP. Each measurement is the mean/standard deviation of a minimum of 3 weighings collected using a Mettler Toledo microbalance. Units are milligrams. Note that Sample 3, which was twice as thick as the other samples, had the smallest \% increase in weight, which raises the question of diffusion rates and gradients in density within a sample. *Sample 4 was chipped between weighings, so its actual increase in mass is larger than shown. The chips from sample 4 are roughly 0.56 and $0.055 \mathrm{~mm}^{2}$ in area, or about $2.4 \%$ of sample 4 's area.

\begin{tabular}{|c|r|r|r|}
\hline Sample & $\begin{array}{r}\text { mean weight } \\
\text { upon receipt } \\
\sigma \text { wt }(\mathrm{mg})\end{array}$ & $\begin{array}{r}\text { mean weight } \\
\text { after 170 days } \\
\sigma \text { wt }(\mathrm{mg})\end{array}$ & \\
\hline 1 & 2.40363 & 2.4766 & 3.04 \\
& 0.00012 & 0.0004 & \\
\hline 2 & 2.4442 & 2.5365 & 3.78 \\
& 0.0010 & 0.0010 & \\
\hline 3 & 4.65373 & 4.7732 & 2.57 \\
& 0.00012 & 0.0004 & \\
\hline 4 & 2.4036 & 2.4306 & $* 1.12$ \\
& 0.0003 & 0.0003 & \\
\hline 5 & 2.4325 & 2.5252 & 3.81 \\
& 0.0003 & 0.0003 & \\
\hline 6 & 2.42457 & 2.51653 & 3.79 \\
& 0.00017 & 0.00012 & \\
\hline 7 & 2.4277 & 2.52190 & 3.88 \\
& 0.0002 & 0.00014 & \\
\hline
\end{tabular}


TABLE IV: Assignment of IR spectra of GDP samples upon receipt and after aging. The most notable change is the increase in $\mathrm{O}-\mathrm{H}$ stretch with aging.

\begin{tabular}{|c|c|c|c|}
\hline $\mathrm{cm}-1$ & intensity & effect of aging? & assignment \\
\hline 778 & weak & & \\
\hline 890 & weak & region not sampled in & \\
\hline 908 & weak & 92 and 172 um samples & \\
\hline 971 & weak & & \\
\hline 1035 & weak & & \\
\hline 1060 & weak & background increased & \\
\hline 1087 & weak & & \\
\hline 1166 & weak & & \\
\hline 1377 & v. strong & saturated & -C-H bend \\
\hline 1453 & saturated & & C-H scissor/bending modes \\
\hline 1609 & strong & blended $\mathrm{w} / \mathrm{C}=\mathrm{O}$ & $\begin{aligned} \text { diene } \mathrm{C} & =\mathrm{C} \text { stretch } \\
\text { conjugated with } \mathrm{C} & =\mathrm{O} \text { stretch }\end{aligned}$ \\
\hline 1704 & saturated & strengthened & $\mathrm{C}=\mathrm{O}$ stretch \\
\hline 1735 & superimposed on $\mathrm{C}=\mathrm{O}$ band & blended $\mathrm{w} / \mathrm{C}=\mathrm{O}$ & \\
\hline 2045 & $\begin{array}{l}\text { v.v. weak } \\
\text { only in } 172 \mu \mathrm{m} \text { sample }\end{array}$ & & \\
\hline 2232 & weak & & \\
\hline 2732 & $\begin{array}{l}\text { sharp; } \\
\text { superimposed on } \mathrm{C}-\mathrm{H} \text { band }\end{array}$ & blended with C-H stretch & $\begin{array}{r}\text { aldehyde C-H stretch } \\
\text { or } 1377 \text { overtone }\end{array}$ \\
\hline 2838 & saturated & lower edge of saturated region & \\
\hline 2900 & saturated & & $\mathrm{C}-\mathrm{H}$ alkane stretches \\
\hline 2986 & saturated & upper edge of saturated region & \\
\hline 3070 & v.v. weak & $\begin{array}{r}\text { present only in } \\
50 \text { and } 70 \text { um samples }\end{array}$ & \\
\hline 3176 & v. weak & gone & \\
\hline 3400 & strong, broad & strengthened, broadened & O-H stretch \\
\hline 3407 & superimposed on $\mathrm{OH}$ band & blended with O-H stretch & $\mathrm{O}-\mathrm{H}$ \\
\hline 3477 & superimposed on $\mathrm{OH}$ band & & $\mathrm{O}-\mathrm{H}$ \\
\hline 3537 & v.v. weak & & \\
\hline 3614 & weak & & free $\mathrm{OH}$ stretch \\
\hline 4065 & weak & & \\
\hline 4171 & weak & & \\
\hline 4261 & weak & & \\
\hline 4333 & medium & & overtone \\
\hline 4597 & weak & & \\
\hline 4785 & weak & appears with age & \\
\hline 5683 & weak & $\begin{array}{r}\text { much weaker in } \\
50 \text { and } 70 \text { um samples }\end{array}$ & overtone $2870 ?$ \\
\hline $\begin{array}{l}5810 \\
5865\end{array}$ & $\begin{array}{l}\text { weak } \\
\text { weak }\end{array}$ & & $\begin{array}{l}\text { overtone } 2980 ? \\
\text { overtone } 3027 ?\end{array}$ \\
\hline 7070 & weak & strengthened & \\
\hline 7232 & weak & strengthened & \\
\hline
\end{tabular}


TABLE V: The role of aging (and associated water/oxygen uptake), vacuum exposure, and silver coatings on the measured thickness of GDP. Each measurement is the mean/standard deviation of a minimum of 13 points collected using a laser micrometer. Units are microns. Side A corresponds to shiny side up. Side B corresponds to the rough/coated side up. $\sigma$ is the standard deviation of the measurements.

\begin{tabular}{|c|c|c|c|c|c|c|c|}
\hline & upon receipt & $\begin{array}{l}\text { pre-vacuum } \\
\text { exposure }\end{array}$ & $\begin{array}{l}\text { post-vacuum } \\
\text { exposure }\end{array}$ & pre-coating & post-coating & $\begin{array}{l}\text { additional } \\
\text { measurements }\end{array}$ & \\
\hline Sample & B & $\mathrm{A} \quad \mathrm{B}$ & $\mathrm{A} \quad \mathrm{B}$ & A & B & A $\quad$ B & side \\
\hline 1 & \begin{tabular}{|cr|}
\multicolumn{2}{|c|}{ 9-Jun-11 } \\
91.23 & 91.23 \\
0.42 & 0.42
\end{tabular} & & & \begin{tabular}{|cr|}
\multicolumn{2}{|c|}{ 10-Feb-12 } \\
92.62 & 91.62 \\
0.62 & 0.49
\end{tabular} & not coated & \begin{tabular}{lr}
\multicolumn{2}{c}{ 12-Jan-12 } \\
92.31 & 92.38 \\
0.61 & 0.49
\end{tabular} & $\begin{array}{c}\text { date } \\
\text { mean } \\
\sigma\end{array}$ \\
\hline 2 & \begin{tabular}{cr}
\multicolumn{2}{c}{ 9-Jun-11 } \\
92.54 & 92.46 \\
0.63 & 1.08
\end{tabular} & \begin{tabular}{lr}
\multicolumn{2}{c}{$22-$ Nov-11 } \\
93.22 & 93. \\
0.42 & 1.17
\end{tabular} & \begin{tabular}{|cr|}
\multicolumn{2}{c|}{$22-$ Nov-11 } \\
93.41 & 94.61 \\
0.49 & 1.77
\end{tabular} & not coat & ed; used for & EM images & $\begin{array}{c}\text { date } \\
\text { mean } \\
\sigma\end{array}$ \\
\hline 3 & \begin{tabular}{lr}
\multicolumn{2}{|c|}{ 9-Jun-11 } \\
192.8 & 173.2 \\
4.26 & 0.42
\end{tabular} & \begin{tabular}{lr}
\multicolumn{2}{c}{$14-$ Dec-11 } \\
197.9 & 174.2 \\
6.27 & 0.42
\end{tabular} & \begin{tabular}{lr}
\multicolumn{2}{c|}{14 -Dec-11 } \\
205.9 & 175.3 \\
5.25 & 0.82
\end{tabular} & \begin{tabular}{|cr|}
\multicolumn{2}{|c|}{ 12-Jan-12 } \\
210.8 & 174.5 \\
4.82 & 0.50
\end{tabular} & $\begin{array}{c}\text { 13-Jan-12 } \\
173.1 \\
0.27\end{array}$ & & $\begin{array}{c}\text { date } \\
\text { mean } \\
\sigma\end{array}$ \\
\hline 4 & \begin{tabular}{|cr|}
\multicolumn{2}{|c|}{ 9-Jun-11 } \\
91.23 & 91.23 \\
0.42 & 0.42 \\
\end{tabular} & & & \begin{tabular}{|cr}
\multicolumn{2}{|c|}{6 -Sep-12 } \\
92.15 & 92.08 \\
0.36 & 0.27
\end{tabular} & $\begin{array}{c}\text { 6-Sep-12 } \\
91.69 \\
0.46\end{array}$ & & $\begin{array}{c}\text { date } \\
\text { mean } \\
\sigma\end{array}$ \\
\hline 5 & \begin{tabular}{|cr|}
\multicolumn{2}{|c|}{ 9-Jun-11 } \\
92.38 & 92.62 \\
0.49 & 0.49
\end{tabular} & & & \begin{tabular}{|cr|}
\multicolumn{2}{|c|}{$1-N o v-11$} \\
98 & 99.19 \\
3.44 & 3.21
\end{tabular} & $\begin{array}{c}\text { 2-Nov-11 } \\
95.81 \\
2.10\end{array}$ & & $\begin{array}{c}\text { date } \\
\text { mean } \\
\sigma\end{array}$ \\
\hline 6 & \begin{tabular}{lr}
\multicolumn{2}{c}{ 9-Jun-11 } \\
92. & 92.31 \\
0 & 0.61
\end{tabular} & \begin{tabular}{lr}
\multicolumn{2}{c}{$14-$ Dec-11 } \\
$92.15 \quad 92$. \\
0.77 & 0
\end{tabular} & \begin{tabular}{|lr|}
\multicolumn{2}{|c|}{14 -Dec-11 } \\
93.46 & 92.85 \\
0.84 & 0.36
\end{tabular} & \begin{tabular}{|cr} 
14-Dec-11 \\
93.46 & 92.85 \\
0.84 & 0.36
\end{tabular} & $\begin{array}{c}\text { 14-Dec-11 } \\
92.85 \\
0.36\end{array}$ & & $\begin{array}{c}\text { date } \\
\text { mean } \\
\sigma\end{array}$ \\
\hline 7 & \begin{tabular}{|cr|}
\multicolumn{2}{|c|}{ 9-Jun-11 } \\
92.15 & 92.08 \\
0.36 & 0.27
\end{tabular} & & & \begin{tabular}{|cr|}
\multicolumn{2}{|c|}{2 -Feb-12 } \\
92.23 & 92.23 \\
0.42 & 0.42
\end{tabular} & $\begin{array}{c}\text { 3-Feb-12 } \\
92 . \\
0\end{array}$ & & $\begin{array}{c}\text { date } \\
\text { mean } \\
\sigma\end{array}$ \\
\hline
\end{tabular}

